\title{
An Empirical Study on Asymmetric and Non-Proportional Price Response Function in the Shipment Timing Decision-Making Support System for Agricultural Products
}

\author{
Youngsik Kwak, Yoonjung Nam ${ }^{* 2}$, Yoonsik $\mathrm{Kwak}^{3}$, Pil Hwa Yoo ${ }^{4}$ and Seokil \\ Song ${ }^{3, a}$ \\ ${ }^{1}$ Gyeongnam National University of Science and Technology \\ ${ }^{2}$ Instructor, Woosong University \\ ${ }^{3}$ Korea National University of Transportation \\ ${ }^{4}$ Graduate School of Business at Sungkyunkwan University (SKK GSB) \\ 1yskwak@gntech.ac.kr, ${ }^{2}$ jean@hanyang.ac.kr, ${ }^{3} y s k w a k @ u t . a c . k r$, \\ ${ }^{4}$ phyoo362@daum.net, ${ }^{a}$ sisong@ut.ac.kr
}

\begin{abstract}
STSS (Shipment Timing Decision-Making Support System for Agricultural Products) is designed to manage shipping dates to improve sales profits for agricultural products that are stored in warehouses. The purpose of this study is to increase the predictability of the price variable among other variables included in this system to better predict wholesale prices at the shipping dates. This study suggests the use of an asymmetric price response function and a non-proportional price response function, which can comprehensively trace price changes in the next period based on price increases or decreases at certain levels in the previous period. Additionally, the study aims to conduct an empirical analysis of the whole market as well as the market segments.

The data used were wholesale prices and delivery volumes for $15 \mathrm{~kg}$ of fine grade Fuji apples traded at Garak Agro-Fishery Market located in Garak-dong, Seoul. The analysis was conducted by market segment, and confirmed periods when the responses towards a given day's price levels were big and small when previous day's price levels for wholesale apples decreased or increased during the year. Through this, the best opportunity to adjust shipping dates of apples and to increase profits could be suggested.
\end{abstract}

Keywords: Asymmetric price response, Non-proportional price response, Price response function, Wholesale price of apple, Segmented market analysis

\section{Introduction}

STSS (Shipment Timing Decision-Making Support System for Agricultural Products) is designed to manage optimal shipping dates to improve sales profits for agricultural products that are stored in warehouses. In this STSS, the suggested output is price level at a certain point of time. With this price level, farmers and wholesalers can decide whether they would ship their agricultural products or not.

Many researchers have suggested variables that predict price levels at certain periods in the STSS and tested their significance. The variables include the total shipment quantity at previous day, wholesale prices at previous day, national holiday effect, the days elapsed after shipping of newly harvested products, substitution price level, the day-of-the-week effects and so on (Kwak, et al., 2011, 2013, 2014).

* Corresponding author 
Among those agricultural product variables from prior studies, this study focuses on improving the marginal point of a price variable used in the existing STSS. First, the price function used in the existing STSS sometimes only measures the amount of the price response without its price change direction: an increase or decrease (Kwak, et al., 2014). The change rate of a dependent variable can be different depending on the price increase or decrease even at one price level, but this is not yet reflected in the existing STSS. According to the Prospect Theory by Kahneman and Tversky (1992), consumers feel differently about utility in terms of a loss (a price increase), or a profit (a price decrease). Therefore, there may be an asymmetric price response for the same price decrease and increase at a certain level. However, research by Kwak, et al., (2014) measured only symmetric price responses rather than asymmetrical responses to a price increase or decrease.

Second, in regards to a price change of one directionality - increase or decrease either a big price change or a small price change will not change the dependent variable at a fixed ratio. In other words, demand can be predicted to show a non-proportional response to a small or big price increase or decrease. According to the Prospect Theory by Kahneman and Tversky (1992), people feel the loss in utility is small when the amount of the loss, namely the price increase, is small. Utility rapidly decreases along with an increase in loss, that is a greater price increase. Utility no longer decreases when the degree of loss is very high. Therefore, it is necessary to measure the non-proportional response effect while ensuring the asymmetry of the directional price increase effect. However, existing STSS studies do not reflect the non-proportional response effect when the amount of the increase or decrease grows larger. Gutenberg's model reflects this phenomenon in existing studies of pricing, however, it can't be found in STSS studies (Kwak, et al., 2011, 2013).

Third, a price response with asymmetric and non-proportional change in acceptance according to price changes was recently measured and reported by market segment, but the studies, which measure asymmetric and non-proportional price response by market segment has not been done (Kwak, 2015).

This study aims to establish a model that can trace non-proportional demand response along with asymmetric price response, with tenable directionality of price change, and to analyze this at the market segment level (Table 1).

Table 1. Positioning of the Study

\begin{tabular}{c|c|c|c|c|c}
\hline \multirow{2}{*}{\multicolumn{2}{c|}{}} & \multicolumn{3}{c}{ Response to price change } \\
\cline { 3 - 5 } & \multicolumn{2}{|c}{ Proportional response } & \multicolumn{2}{c}{ Non-proportional response } \\
\cline { 3 - 6 } & Whole & Segment \\
market & market & Whole market & $\begin{array}{c}\text { Segment } \\
\text { market }\end{array}$ \\
\hline \multirow{2}{*}{$\begin{array}{c}\text { Price change } \\
\text { (increase or } \\
\text { decrease) }\end{array}$} & $\begin{array}{c}\text { None } \\
\text { (symetric response } \\
\text { expected) }\end{array}$ & $\begin{array}{c}\text { Economical } \\
\text { price } \\
\text { elasticity }\end{array}$ & $\begin{array}{c}\text { Yes } \\
\text { (asymmetric response } \\
\text { expected) }\end{array}$ & $\begin{array}{c}\text { Gutenberg's } \\
\text { price response } \\
\text { function }\end{array}$ & \\
\hline
\end{tabular}




\section{Literature Review}

\subsection{Prospect Theory and Asymmetric/Non-proportional Price Response Function}

Prospect theory is a theory that assumes people are more sensitive about losses than gains, and that gains and losses are evaluated based on a reference point, and the utility of both gains and losses have a diminishing relationship (Kahneman \& Tversky, 1992).

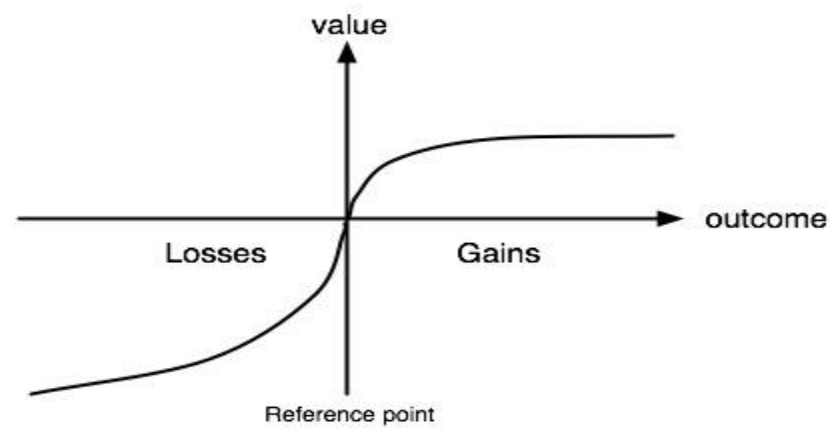

Figure 1. Value Function of the Prospect Theory

Price response function refers to measuring changes in demand according to changes in price, and it is shown in a function. A function, which traces changes in price and in demand at present or in the future, depending on changes in price in the past, by granting a temporal factor to the price response function, is called dynamic price response function. Asymmetric price response function refers to a function that traces asymmetric changes in a dependent variable, which responds to the amount of the same price increase or decrease at a certain price level. Nonproportional price response function refers to a price response function when the amount of changes in a dependent variable is not consistent if there is an increase in a price change (Simon, 1987).

The following characteristics can be found when prospect theory is applied to a price response function: First, because people are more sensitive about the loss, called the price increase, than the gain, called the price decrease, changes in response to the same amount of a price increase and a price decrease are not symmetric. In other words, an asymmetric price response function can explain a price response phenomenon better than a symmetric price response.

Second, the utility for both the gain (price decrease) and the loss (price increase) have a diminishing relationship. Accordingly, when the amount of a price increase or decrease becomes larger, changes in a dependent variable including demand are not proportional. Therefore, a non-proportional price response function can explain the price response phenomenon better than a proportional price response function.

\subsection{Study on Price Response Functions based on Prospect Theory}

A price response function model used by Kwak et al., $(2011,2013,2014)$ in the STSS for apples is shown in equation (1).

$$
\mathrm{q}_{t}=a_{t}-\mathrm{bp}_{t}
$$

Here, $b$ refers to the change in rate of demand, a dependent variable, when the price of one unit changes. Equation (1) is not related to the price level, and it measures only $b$, the change in rate of demand, regardless of the amount of the price change and the 
directionality of it. In other words, it has the limitation of assuming that sales change consistently every time there is a one unit change in price.

It is possible to suggest various types of price response functions to use in STSS. As in equations (2) and (3), symmetric but non-proportional price responses can be modeled. These two equations can reflect a situation in which sales volume or market share does not drop perceptibly in a case with small changes in the current price at the current price level. On the other hand, if the price change or the price drifts far away from the current price, the demand will rapidly increase or decrease with its directionality. This function has been applied in other industries but not yet in the agricultural industry (Simon, 1982; Baek, et al., 2003). However, this model does have the weakness of showing a symmetric demand response regardless of the increase or decrease in price.

$$
\begin{gathered}
\mathrm{q}_{\mathrm{i}}=\mathrm{a}\left(\mathrm{p}_{\mathrm{i}} / \overline{\mathrm{p}}\right) \mathrm{b} \\
\mathrm{q}=\mathrm{a}-\mathrm{bp}-\mathrm{c}_{1} \sinh \left[\mathrm{c}_{2}\left(\mathrm{p}_{\mathrm{i}}-\overline{\mathrm{p}}\right)\right]
\end{gathered}
$$

Equation (4) was modeled based on equation (1) so that changes in a price increase and decrease can have directionality. This equation separately measures the effects of a price increase and decrease. In other words, it can trace the asymmetric price response. However, as shown in equations (2) and (3), it cannot measure non-proportional responses.

$$
q_{t}=a_{t}-c\left(p_{t}-p_{t-1}\right)+-d\left(p_{t}-p_{t-1}\right)-e p_{t}
$$

The purpose of this study is to present a model that traces non-proportional price responses with the directionality of the price increase or decrease based on price changes and simultaneously measure non-proportional changes in demand.

Therefore, this study completed modeling by integrating equation (3) so that changes in a price increase and a price decrease can have directionality, with equation (4) as the basic equation.

$$
\begin{aligned}
& \mathrm{q}_{\mathrm{t}+1}=\mathrm{a}_{\mathrm{t}}-\mathrm{bp}_{\mathrm{t}}-\mathrm{c}_{1} \sinh \left[\mathrm{c}_{2}\left(\mathrm{p}_{\mathrm{t}}-\mathrm{p}_{\mathrm{t}-1}\right)\right]^{+}-\mathrm{c}_{\mathrm{a}} \sinh \left[\mathrm{c}_{4}\left(\mathrm{p}_{\mathrm{t}}-\mathrm{p}_{\mathrm{t}-1}\right)\right]^{-} \\
& \mathrm{P}_{\mathrm{t}+1}=\mathrm{a}_{\mathrm{t}}-\mathrm{b} \mathrm{Q}_{\mathrm{t}}-\mathrm{c}_{1} \sinh \left[\mathrm{c}_{2}\left(\mathrm{p}_{\mathrm{t}}-\mathrm{p}_{\mathrm{t}-1}\right)\right]^{+}-\mathrm{c}_{\mathrm{a}} \sinh \left[\mathrm{c}_{4}\left(\mathrm{p}_{\mathrm{t}}-\mathrm{p}_{\mathrm{t}-1}\right)\right]^{-}
\end{aligned}
$$

STSS is meant to measure future prices, and therefore, the new system should be changed to dynamic price response function based on equation (4). Dynamic price response function refers to a function that traces the effects of prices in the past, which changes with a time lag, on current or future prices and demand. Therefore, this study conducted modeling by changing the form of equation (5) to equation (6) to enable price changes in the past to predict future ones. c2 in equation (6) is the non-proportional calculation of the effect of a price increase from the previous period to the present one on prices in the following period. $\mathrm{c} 3$ is the non-proportional calculation of the effect of a price decrease from the previous period to the present one on prices in the next period. $b$ is the calculation of the effect of the shipping amount in the present period on prices in the next period. This study suggests that equation (6) is a model suitable to meet the study's purpose.

\section{Research Methodology}

\subsection{Sample and Data Collection}

The data used here are price data on $15 \mathrm{~kg}$ of fine grade Fuji apples sold at the wholesale agro-fishery market in Garak-dong, with transaction volume on a relevant date (www.garak.co.kr). This study chose apples as a product example that enabled price identification and sales over a long period of time. Fuji apples produced in the current year are first shipped in September or October and stored apples are sold in markets until the summer of the following year. Therefore, it is possible to trace prices and sales volume for nearly a year. This study limited the apple grade to fine grade, following the 
argument made by Garak Market that fine grade apples can be representative of all apples as they are sold the most among all four grades.

The analysis data were transactions of apples from October 15, 2009, the date Fuji apples were first transacted that year, to April 30, 2015. The number of transaction dates used as samples was 1,503 , and as this study used the observations of the first day as a basis to trace price changes, 1,502 were used as transaction observations.

\subsection{Modification of the Model Considering the Nature of Agricultural Product Data}

In terms of the apple delivery amounts, there is a possibility that the delivery amounts during holidays, such as Chuseok (Thanksgiving Day) and Seol (Lunar New Year's Day), may be different from that on ordinary days. Kwak (2015) reported that the delivery amounts before those holidays was greater than during ordinary days, and decreased after those holidays. Additionally, Lee, et al., (2012) reported that there is a day of the week effect on agricultural products and prices. Therefore, this study developed a model with the holiday effect and the day of the week effect added to the basic model of equation (6).

$$
\begin{aligned}
& \mathrm{P}_{\mathrm{t}+1}=\mathrm{a}_{\mathrm{t}}-\mathrm{b} \mathrm{Q}_{\mathrm{t}}-\mathrm{c}_{1} \sinh \left[\mathrm{c}_{2}\left(\mathrm{p}_{\mathrm{t}}-\mathrm{p}_{\mathrm{t}-1}\right)\right]^{+}-\mathrm{c}_{3} \sinh \left[\mathrm{c}_{4}\left(\mathrm{p}_{\mathrm{t}}-\mathrm{p}_{\mathrm{t}-1}\right)\right]^{-}+\text {dday }_{\mathrm{t}}+ \\
& \text { ebefore } \mathrm{t}_{\mathrm{t}}+\text { fafter }_{\mathrm{t}}
\end{aligned}
$$

\subsection{Operational Definition}

The daily apple wholesale transaction volume of Garak Agro-Fishery Market is used as the dependent variable in equation (7). This is because the market does not only announce the transaction volume of Fuji apples but price, an independent variable in equation (7), is measured by changes in the daily wholesale prices of $15 \mathrm{~kg}$ of Fuji apples. In other words, equation (7) calculates the difference between the average price for the previous day and today of the wholesale transaction volume for $15 \mathrm{~kg}$ of fine grade Fuji apples. The average price is used because same grade apples are sold at different prices on the same day. The days from Monday to Saturday were incorporated as dummy models to examine the day of the week effect, and two weeks before and after the holidays were coded to dummy variables to examine the holiday effect.

\section{Empirical Analysis}

\subsection{Deduction of a Model Coefficient for the Whole Market}

The purpose of this study is to present and to analyze empirically a dynamic model that traces non-proportional price responses with the directionality of the price increase or decrease based on price changes and simultaneously measure non-proportional changes in demand. This study substituted apple wholesale price and delivery volume data in equation (7). Table 1 shows the result of linear regression analysis using LatendGold software program.

Table 2. Result of Regression Analysis by Model

\begin{tabular}{|c|c|c|c|}
\hline variable & $\begin{array}{c}\text { Regression coefficient for the } \\
\text { whole market }\end{array}$ & Wald & p-value \\
\hline Intercept value (a) & 54296.53 & 1694.52 & $2.1 \mathrm{E}-370$ \\
\hline $\begin{array}{c}\text { Effect of delivery volume in } \\
\text { the previous period (b) }\end{array}$ & -66.25 & 249.62 & $3.1 \mathrm{E}-56$ \\
\hline Effect of price increase (C1) & 0.0912 & 30.82 & $2.8 \mathrm{E}-08$ \\
\hline Effect of price decrease (C2) & -0.0416 & 7.72 & 0.0055 \\
\hline Day of the week effect - Mon. & 1828.46 & 11.06 & 0.05 \\
\hline
\end{tabular}




\begin{tabular}{|c|c|c|c|}
\hline Day of the week effect - Tue. & 375.48 & \multirow{3}{*}{} & \multirow{2}{*}{} \\
\cline { 1 - 2 } Day of the week effect - Wed. & 201.16 & \\
\cline { 1 - 2 } Day of the week effect - Thu. & 312.29 & \\
\hline Day of the week effect - Fri. & -873.4 & & \\
\hline Day of the week effect - Sat. & -1844.0 & 33.89 & \multirow{3}{*}{$5.8 \mathrm{E}-09$} \\
\hline Holiday effect - prior (e) & 4729.66 & 53.02 & \\
\hline Holiday effect - post (f) & -5333.73 & \multicolumn{3}{|c}{0.186} \\
\hline R-square & & \\
\hline
\end{tabular}

The results show that the delivery volume of the previous period had an effect on the current period. In other words, wholesale prices in the current period increased when the delivery volume of the previous period decreased. In terms of the price increase effect, prices in the current period increased when prices were increased in the previous period and the previous-previous period before that. This effect was also statistically significant ( $c 2=-0.0416, \mathrm{p}=0.0055)$. This means that prices in the current period tend to show an increasing trend if they had an increasing trend in the past. In the case where prices in the previous period and the period before that showed a decreasing trend, the current period tended to show a decreasing trend as well, and the effect was also statistically significant. Meaning, prices in the current period tend to show a decreasing trend if they showed a decreasing trend in the past.

From the analysis of the effect of days, a coefficient was deduced from the data that prices on Mondays and Tuesdays were higher and Fridays and Saturdays lower. The analysis revealed that apple owners were able to request relatively higher prices when they shipped apples on Mondays and Tuesdays compared to other days.

Examining the holiday effect, prices were higher before the holidays and lower after the holidays, and these trends were statistically significant. R-squared value of the regression analysis was 0.186 .

\subsection{Deduction of a Model Coefficient for the Segmented Market}

The analysis unit in equation (7) was the whole market. In this section, the study deducts a linear regression equation by market segment using mixture regression model (Wedel \& Desarbo, 1995; Wedel \& Kamakura, 2000). As the result of testing model fit BIC, BIC decreased when the number of market segments increased from two to three. In other words, it showed the best model fit when explained with two regression equations, as errors increased when explained with three equations. BIC refers to a difference in maximum likelihood values between the observation and the measurement model, thus a smaller value is regarded to have higher explanation power. In other words, two equations with the same form as equation (7), hiding in this observation, are shown as one equation in the whole market. In analyzing the sample with two segmented markets, the explanation power of observation increased to 0.679 .

Table 3. Model Fit by the Number of Segmented Markets

\begin{tabular}{|c|c|c|c|}
\hline $\begin{array}{c}\text { Number of segmented } \\
\text { markets }\end{array}$ & BIC & $\begin{array}{c}\text { Estimated number of } \\
\text { parameters }\end{array}$ & R-square \\
\hline 1 & 32714 & 12 & 0.186 \\
\hline 2 & 33361 & 25 & 0.679 \\
\hline 3 & 32263 & 38 & 0.831 \\
\hline
\end{tabular}

As the result of calculating the size of each segment, S1 (market segment 1) and S2 (market segment 2) made up $86.7 \%$ and $13.3 \%$ of the entire sample, respectively. 
The average price of the transactions in S1 was KRW 44,529, and for S2, the average price was KRW 55,464. In the segmented market analysis, all the independent variables, price increase effect, delivery volume effect, day of the week effect, and holiday effect were significant at a 99\% confidence level. The signs of the variables of S1 and S2 almost coincided. The effect of a delivery volume in the previous period on current apple wholesale prices was negative. The price increase effect of the previous period had a positive effect on current prices, and the price decrease effect had a negative effect on current prices. Examining the size differences between the price increase effect and the price decrease effect, more decrease effects were shown in S2 than S1. In the case of the day effect, except for the sign being negative on Wednesdays in S2, there was no day effect on signs in either S1 or S2. Additionally, the effect of prices before and after the holidays was greater in S2 than in S1.

This study conducted a posterior probability analysis to identify which transactions belonged to which of the two market segments. As a result, transactions belonging to S2 were found mainly between March 21 and June 29, 2012 for stored Fuji apples produced the autumn of 2011. They were also found between July 25 and August 22, 2013. If we consider this result, the apples produced in the autumn of the previous year appear to be included in the S1 equation until the spring of the following year, and in the S2 equation the summer before new apples are released.

Table 4. Regression Analysis Results by Model

\begin{tabular}{|c|c|c|c|}
\hline \multirow{2}{*}{ variable } & \multirow{2}{*}{$\begin{array}{c}\text { Regression coefficient } \\
\text { for the whole market }\end{array}$} & \multicolumn{2}{|c|}{$\begin{array}{c}\text { Regression coefficient for segmented } \\
\text { markets }\end{array}$} \\
\cline { 3 - 4 } & 54296.53 & 47621.20 & 93965.99 \\
\hline Intercept value (a) & -66.25 & -29.47 & -325.23 \\
\hline $\begin{array}{c}\text { Effect of delivery volume in } \\
\text { the previous period (b) }\end{array}$ & 0.0912 & 0.058 & 0.114 \\
\hline Effect of price increase (C1) & -0.0416 & -0.013 & -0.166 \\
\hline Effect of price decrease (C2) & 1828.46 & 966.5 & 6712.4 \\
\hline Day of the week effect - Mon. & 375.48 & 362.3 & 1168.2 \\
\hline Day of the week effect - Tue. & 201.16 & 179.8 & -564.0 \\
\hline Day of the week effect - Wed. & 312.29 & 97.5 & 2664.7 \\
\hline Day of the week effect - Thu. & -873.4 & -1451.5 & 2815.6 \\
\hline Day of the week effect - Fri. & -1844.0 & -124.6 & -12796.8 \\
\hline Day of the week effect - Sat. & 4729.66 & 3578.12 & 4337.37 \\
\hline Holiday effect - prior (e) & -5333.73 & -3835.35 & -7506.32 \\
\hline Holiday effect - post (f) & 0.186 & \multicolumn{3}{|c|}{0.675} \\
\hline R-square & $100 \%$ & $86.7 \%$ & $13.3 \%$ \\
\hline
\end{tabular}

\section{Conclusion}

The shipping date support system is designed to manage shipping dates to improve sales profits for agricultural products stored in warehouses. Many agricultural studies have been conducted in Korea on transportation and storage management systems from orchard to warehouse. However, not many have been conducted on a system that utilizes detailed shipping dates from warehouse to market (Seo \& Woo, 2007; Kwak, et al., 2014).

The purpose of this study was to improve the predictability of the price variable among other variables included in this system to predict wholesale prices at relevant shipping 
dates. This study suggested an asymmetric, non-proportional and dynamic price response function, which can comprehensively trace changes in prices in the next period, which are affected by a price increase or decrease at a certain level in the previous period. Additionally, this study conducted an empirical analysis of the whole market and the market segments on the shipment of apples, one of the four major fruits produced in Korea.

The data used were wholesale prices and delivery volumes for $15 \mathrm{~kg}$ of fine grade Fuji apples traded at Garak Agro-Fishery Market located in Garak-dong, Seoul. This study conducted an analysis by market segment and confirmed periods when the response towards today's price levels were big and small when yesterday's wholesale price levels decreased or increased for apples during the year. Moreover, it could predict future price levels based on a price increase or decrease in the past. Through this, companies can adjust daily shipping dates of apples based on delivery volumes trends and the increase or decrease of prices in the past, enabling opportunities to improve profits. In addition, this study may strengthen the internal algorithm of the price level prediction program of the shipping date support system.

The academic contribution of this study is that it analyzed the performance of agricultural product prices, which not many previous studies had done compared to other industries in Korea (Seo \& Woo, 2007). In addition, it performed a quantitative price study in an area with relatively low past study performance by suggesting asymmetric and non-proportional price response function and conducting an empirical analysis accordingly.

\section{Acknowledgements}

This work was supported by Gyeongnam National University of Science and Technology Grant in 2015.

\section{References}

[1] J. Baik, S. Hwang and S. Lee, Journal of the Korean Society of Clothing and Textiles, vol. 27, no. 8, (2003), pp. 1004-1013.

[2] M. Wedel and W. S. Desarbo, Journal of Classification, vol. 12, (1995), pp. 1-35.

[3] D. Kahneman and A. Tversky, Econometrica, vol. 47, no. 2, (1979), pp. 263.

[4] Y. Kwak, Korea Journal of business administration, vol. 28, no. 2, (2015), pp. 769-779.

[5] Y. Kwak, S. Song and Y. Kwak, Communications in computer and information science, vol. 264, (2011), 144-152.

[6] Y. Kwak, Y. Nam, Y. Kwak and Y. Lee, International Journal of smart home, vol. 7, no. 6, (2013), pp. 171-180.

[7] M. Lee, S. Hwang and Y. Kwak, Journal of the Korean Society of Clothing and Textiles, vol. 36, no. 4, (2012), pp. 422-431.

[8] S. Seo and S. Woo, Journal of Korean agriculture and economics, vol. 48, no. 2, (2007), pp. 93-113.

[9] S. Song, H. Shin, B. Gu, B. Lee, Y. Kwak and Y. Kwak, Asia life science supplement, vol. 11, (2015), pp. 383-393.

[10] R. Dolan and H. Simon, "Power Pricing”, Free Press, New York, (1997).

[11] Kluwer Academic Publisher, Boston, (2000).

[12] Y. Kwak, J. Hong and Y. Lee, Strategic Pricing, Benet, Seoul, (2007).

[13] T. Nagle, "The Strategy and Tactics of Pricing", Englewood Cliffs, (1995).

[14] H. Simon, "Price Management", Free Press, (1987).

[15] M. Wedel and W. Kamakura, "Market Segmentation: Conceptual and Methodological Foundations", Kluwer Academic Publisher, Boston, (2000).

[16] P. Yoo, "Pricing policy: Theory and Its Application", Parkyoungsa, Seoul, (1991).

[17] P. Yoo, H. Simon and M. Pasnahart, "Management of Price", Parkyoungsa, Seoul, (2012), www.garak.co.kr. 


\section{Authors}

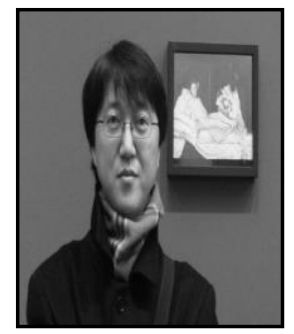

Youngsik Kwak, $\mathrm{He}$ received a B.B.A. degree from Sungkyunkwan University, Seoul, Korea, in 1990, an MBA. degree from Sungkyunkwan University, Seoul, Korea, in 1994, a M.S. degree from Texas Tech University, Lubbock, TX, in 1997, and a Ph. D. degree from Sungkyunkwan University, Seoul, Korea in 1999, in marketing. He had been a marketing consultant for Daewoo Economic Research Institutes from 1999 to 2002. Currently he is an associate professor in the Department of Venture and Business, Gyeongnam National University of Science and Technology, Jinju, Korea. His research interests include pricing on- and off-line.

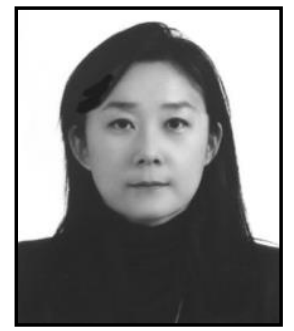

Yoonjung Nam, She received a B.B.A. degree from Sangmyung University, Korea in 1996, an MBA. Degree from Sungkyunkwan University, Korea in 1999, and now is a Ph.D. candidate in Hanyang University, Korea in tourism. She has been a marketer for 2 years in IT industry and 15 years for hospitality industry from 1999 to present. Her research interests include all aspects of hospitality and leisure business and marketing.

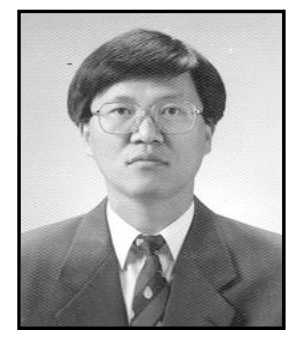

Yoonsik Kwak, He received his B.S. degree in Electrical Engineering from the University of Cheongju in 1984, his M.S.E.E. degree from the University of Kyunghee in 1986 and his Ph.D. degree from the University of Kyunghee in 1994. He worked at Korea National University of Transportation in the Department of Computer Engineering and rose to the level of Full Professor. His research interests are in the areas of signal processing, Internet communication, microcomputer system, and applications of these methods to mobile system.

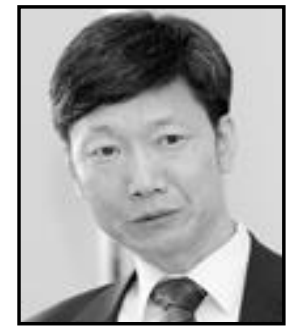

Pil Hwa Yoo, He received his BBA from Seoul National University in 1979, his MBA from Northwestern University in 1981, and his DBA from Harvard University in 1986. Since 1987 he has been teaching marketing at Sungkyunkwan University and served as the Dean of SKK Graduate School of Business from 2012 to 2014 at that university. His research areas are pricing, global marketing, and marketing strategy.

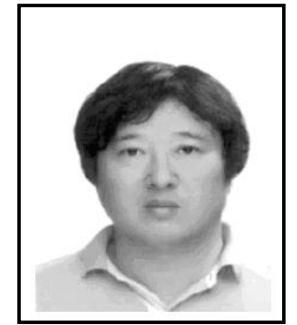

Seokil Song, He received B.S., M.S., and Ph.D. degrees in computer and communication engineering from Chungbuk National University in 1998, 2000, and 2003, respectively. Currently, he is an associate professor in the Department of Computer Engineering at Korea National University of Transportation, Chungbuk, Korea. His research interests include database management systems, concurrency control, high dimensional index structures, storage systems, moving object database, sensor network, and XML database. 
International Journal of $u-$ and $e-$ Service, Science and Technology Vol.8, No. 7 (2015) 